\title{
Pengembangan Wireless Sensor Network Berbasis Internet of Things untuk Sistem Pemantauan Kualitas Air dan Tanah Pertanian
}

\author{
Ummi Syafiqoh $^{1 *}$, Sunardi' ${ }^{2)}$, Anton Yudhana ${ }^{3)}$ \\ ${ }^{1}$ Magister Teknik Informatika, Universitas Ahmad Dahlan, Yogyakarta \\ ${ }^{1}$ Sistem Informasi, STMIK PPKIA Tarakanita Rahmawati, Tarakan \\ ${ }^{2,3}$ Teknik Elektro, Universitas Ahmad Dahlan, Yogyakarta \\ 1,2,3Jln. Prof. Dr. Soepomo SH, Warungboto, Umbulharjo, Yogyakarta, 55164, Indonesia \\ ${ }^{1} J 1 n$. Yos Sudarso 8, Tarakan, Kalimantan Utara, 77114, Indonesia \\ email: ${ }^{1}$ ummi1707048013@webmail.uad.ac.id, ${ }^{2}$ sunardi@mti.uad.ac.id, ${ }^{3}$ eyudhana@ee.uad.ac.id
}

Received: 30 Maret 2018; Revised:14 Mei 2018; Accepted: 17 Mei 2018

Copyright (C2018 Politeknik Harapan Bersama Tegal. All rights reserved

\begin{abstract}
Water and soil quality is very important in agriculture. The level of acidity $(\mathrm{pH})$ and soil temperature is one of the things that affect the fertility of plants. Therefore the quality of water and soil on agricultural land is one of the important things that need special attention in its management. One solution to water and soil quality can be monitored and managed efficiently is by utilizing the Wireless Sensor Network based on the Internet of Things (IoT). Use of ESP8266 Module as a WIFI module, widely used by Internet-based applications of Things because the price is cheap, thus reducing many costs and have a pretty good speed of $80 \mathrm{MHz}$. This research aims to develop the concept of Wireless Sensor Network by utilizing ESP8266 module to monitor pH value using pH Meter Analog Kit sensor and temperature of agricultural land using DS18B20 Waterproof sensor. The result of temperature measurement accuracy using DS18B20 Waterproof sensor of the designed system is 99.09\% while the pH measurement using $\mathrm{pH}$ Meter Analog Kit sensor is $91.33 \%$.
\end{abstract}

Abstrak - Kualitas air dan tanah merupakan hal yang sangat penting dalam bidang pertanian. Tingkat keasaman $(\mathrm{pH})$ dan suhu tanah merupakan salah satu hal yang mempengaruhi kesuburan tanaman. Oleh karena itu kualitas air dan tanah pada lahan pertanian merupakan salah satu hal penting yang perlu mendapat perhatian khusus dalam pengelolaannya. Salah satu solusi agar kualitas air dan tanah dapat dipantau dan dikelola dengan efisien adalah dengan memanfaatkan Wireless Sensor Network berbasis Internet of Things (IoT). Penggunaan Modul ESP8266 sebagai modul WIFI, banyak dimanfaatkan oleh aplikasi berbasis Internet of Things karena harganya murah sehingga mengurangi banyak biaya serta memiliki kecepatan yang cukup baik yaitu 80 MHz. Penelitian ini

*) Corresponding author: Ummi Syafiqoh Email : ummi1707048013@webmail.uad.ac.id bertujuan untuk mengembangkan konsep Wireless Sensor Network dengan memanfaatkan modul ESP8266 untuk memantau nilai pH menggunakan sensor pH Meter Analog Kit dan suhu dari lahan pertanian menggunakan sensor DS18B20 Waterproof. Hasil akurasi pengukuran suhu menggunakan sensor DS18B20 Waterproof dari sistem yang dirancang adalah $\mathbf{9 9 . 0 9 \%}$ sedangkan pengukuran pH menggunakan sensor pH Meter Analog Kit sebesar 91.33\%.

Kata Kunci - Wireless Sensor Network, Internet of Things, Modul ESP8266.

\section{I.PENDAHULUAN}

Air sangat penting bagi semua aspek kehidupan di bumi ini. Diantaranya adalah dalam bidang pertanian, air digunakan dalam proses fotosintesis tanaman. Air yang memiliki kualitas yang baik adalah jika air tidak tercemar secara berlebihan oleh zat-zat kimia atau mineral yang berbahaya. Salah satu indikator bahwa air sudah tercemar adalah terjadi perubahan suhu dan pH (derajat keasaman) air. Suhu yang terlalu panas pada air akan mengganggu pertumbuhan tanaman dan mikroorganisme lainnya. Sedangkan $\mathrm{pH}$ air yang normal mempunyai $\mathrm{pH}$ yang berkisar antara 6,5-7,5 [1].

Pada lahan pertanian, penggunaan pupuk sangatlah berpengaruh untuk memperkaya unsur hara dalam tanah sehingga menyuburkan tanaman. Akan tetapi di sisi lain penggunaan pupuk secara terus menerus juga memiliki dampak negatif terhadap kualitas air dan tanah pertanian, diantaranya dapat mengubah $\mathrm{pH}$ tanah dan mengganggu keseimbangan unsur hara dalam tanah. Oleh karena itu kualitas air dan tanah pada lahan pertanian merupakan salah satu hal penting yang perlu mendapat perhatian khusus dalam pengelolaannya.

Salah satu solusi agar kualitas air dan tanah dapat dipantau dan dikelola dengan efisien adalah dengan memanfaatkan Wireless Sensor Network berbasis Internet of Things. Wireless Sensor Network (WSN) adalah suatu infrastruktur 
jaringan nirkabel yang terdiri dari sejumlah node sensor yang tersebar di suatu area. Teknologi WSN dapat digunakan untuk memonitor beberapa hal seperti temperatur, kelembaban, kondisi cahaya, level derau, pergerakan suatu objek dan lain sebagainya. Sehingga dapat disimpulkan bahwa WSN adalah sebuah penghubung antara lingkungan fisik (physical world) dan dunia digital (digital world) [2].

Modul ESP8266 merupakan modul WIFI, yang banyak digunakan untuk aplikasi Internet of Things seperti mengendalikan aktuator dan membaca sensor. Sistem pengendalian tersebut dapat berbentuk protokol MQTT ataupun webserver yang tertanam dalam memory IC ESP8266 tersebut [3].

\section{II.PENELITIAN YANG TERKAIT}

Beberapa penelitian yang terkait atau berkaitan dengan penelitian ini diantaranya yaitu Saputra, T. R.M.,dkk (2017) yang melakukan penelitian berjudul "penerapan wireless sensor network berbasis internet of things pada kandang ayam untuk memantau dan mengendalikan operasional peternakan ayam", sistem yang dibuat dalam penelitian ini bertujuan sebagai alternatif pemeriksa kandang ayam, sehingga para pekerja tidak terlalu sibuk untuk memeriksa kondisi kandang ayam secara terus menerus. Sistem yang dibuat juga mampu mengendalikan suhu di dalam kandang peternakan sesuai dengan umur ternak. Pada penelitian ini sensor yang digunakan adalah sensor suhu, kelembababan dan sensor berat. Sensor-sensor tersebut bekerja dengan mengirim data hasil pengukuran yang diterimanya ke cloud melalui jaringan wifi. Setiap sensor akan dihubungkan dengan ESP8266. ESP8266 berfungsi sebagai pengganti microkontroller dan juga dilengkapi dengan modul wifi untuk mengirim data dari sensor menuju cloud/database [3].

Sridharan, S (2014) melakukan penelitian dengan judul "water quality monitoring system using wireless sensor network". Penelitian ini bertujuan untuk mendesain dan merancang sebuah jaringan sensor nirkabel yang dapat memantau kualitas air. Parameter kualitas air yang diukur diantaranya tingkat keasaman $(\mathrm{pH})$, suhu dan tingkat kekeruhan air. Media transmisi data dari sensor yang digunakan berbasis teknologi Zigbee serta perancangan platform GUI menggunakan aplikasi MATLAB [4].

Fuad, M (2015) melakukan penelitian yang berjudul "rancang bangun wireless sensor network berbasis protokol zigbee dan GSM untuk sistem pemantauan polusi udara". Penelitian ini menggunakan 7 node sensor yang diletakkan pada tempat yang memiliki tingkat peluang polusi udara cukup tinggi di area kampus IPB Dramaga. Tempat tersebut yaitu di pinggir jalan utama kampus. Protokol zigbee dengan topologi mesh digunakan sebagai protokol komunikasi antar node sensor, sehingga setiap node dapat saling berkomunikasi secara nirkabel sesuai dengan radius yang dapt dijangkaunya. Tiga mekanisme kerja yang dibentuk terdiri dari coordinator, router dan end device. Perangkat yang berfungsi sebagai pengambil data pengukuran yaitu router dan end device, kemudian node sensor yang telah mengambil data pengukuran mengumpulkannya pada satu coordinator (node sink) dan melalui jaringan komunikasi GSM data tersebut dikirim ke server [5].

Sabiq, A.,dkk (2017) melakukan penelitian yang berjudul "sistem wireless sensor network berbasis arduino uno dan
Raspberry Pi untuk pemantauan kualitas udara di cempaka putih timur, Jakarta Pusat”. Pada penelitian ini dipaparkan pengembangan WSN pada platform perangkat keras open source, yaitu Arduino pada node sensor dan Raspberry $\mathrm{Pi}$ pada node sink. Setiap node terhubung melalui jaringan mesh berbasis Zigbee menggunakan modul Xbee Series-2. Dari hasil pengujian didapatkan sistem WSN yang dirancang dapat memantau data udara seperti suhu, kelembaban, kadar $\mathrm{CO}$ dan $\mathrm{CO}_{2}$ serta menyimpannya ke dalam database. Informasi kualitas udara tersebut dapat ditampilkan pada sink ataupun perangkat lain yang terhubung ke jaringan lokal melalui aplikasi web [6].

Khoiruddin, N.F.,dkk (2015) melakukan penelitian yang berjudul "sistem pemantauan kondisi tanah sawah sebagai referensi pemupukan padi berbasis wireless sensor network", rancangan penelitian ini terdiri dari empat buah node dan routing multi point to point, dimana setiap node terdiri dari tiga jenis sensor yaitu sensor kelembaban, sensor suhu LM35, serta sensor keasaman tanah $(\mathrm{PH})$ yang diintegrasikan dengan mikrokontroler ATMEGA8535 dan bahasa pemograman CVAVR. Proses transmisi data dari sensor ke server dikirim melalui Wireless Sensor Network menggunakan interface XBee Series 2. Data yang diolah ditampilkan pada sebuah PC menggunakan software processing untuk pemantauan perubahan pengukuran yang terjadi pada masing-masing sensor node [7].

Yudhana, A., dkk (2016) melakukan penelitian yang berjudul "penyiram tanaman otomatis berbasis informasi sinyal sensor kelembaban". Penelitian ini bertujuan untuk mengubah cara penyiraman yang awalnya manual menjadi otomatis berdasarkan informasi yang diperoleh dari sensor kelembaban yang dipasang dalam tanah. Jika kadar air kurang dari $32.6 \%$ maka pompa air akan hidup secara otomatis dan mulai untuk menyirami tanaman sebaliknya jika kadar air dalam tanah telah mencapai lebih dari $32.6 \%$ makan pompa air akan mati dan berhenti menyalurkan air pada tanaman. Alat yang digunakan yaitu mikrokontroller ATMEGA8535, Kontraktor Elektronik (Relay), LCD, catudaya dan sensor kelembaban tanah (soil moisture sensor) [8].

Penelitian yang dilaksanakan saat ini yaitu pengembangan sebuah Wireless Sensor Network menggunakan modul WIFI ESP8266 untuk memantau kualitas air dan tanah pertanian, sehingga data seperti $\mathrm{pH}$ dan suhu dari lahan pertanian dapat tersimpan dan terpantau melalui node sink serta perangkat lain yang terhubung ke node sink melalui jaringan lokal. Penelitian ini bertujuan untuk mengolah data dari kualitas air dan tanah dari lahan pertanian secara cerdas dan kreatif dengan pemanfaatan teknologi informasi dan komunikasi. Hasil pemanfaatannya diharapkan mampu membantu para petani untuk menjadikan sistem pertanian dalam upaya pengawasan dan pengendalian kualitas air dan tanah pertanian menjadi lebih efisien. [9]

\section{III.METODE PENELITIAN}

Metode penelitian yang digunakan dalam penelitian ini adalah sebagai berikut:

\section{A. Perancangan Sistem}

Rancangan sistem yang akan dibuat yaitu, sistem akan memiliki beberapa node sensor dan sebuah node sink yang terhubung dalam sebuah jaringan wireless agar dapat 
memantau $\mathrm{pH}$ tanah, suhu dan kelembababan dari lahan pertanian. Posisi node sensor akan tersebar pada area pemantauan dan memiliki jarak yang bervariasi terhadap node sink.

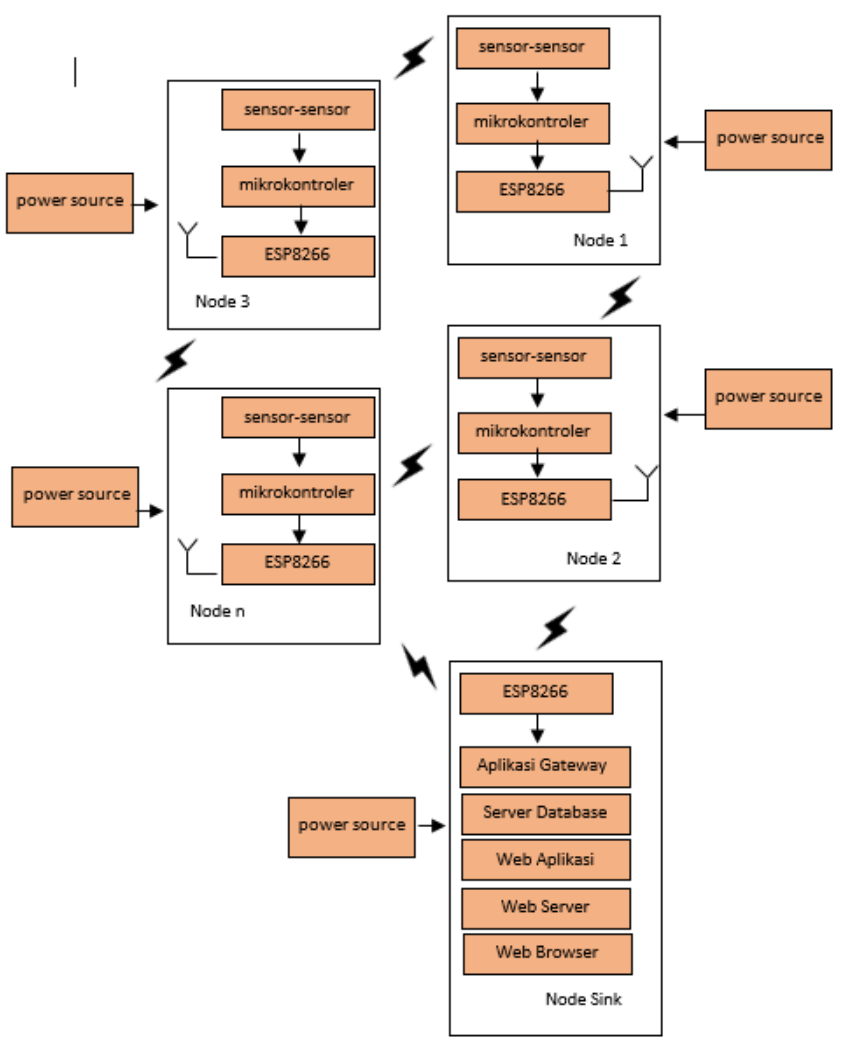

Gbr 2. Rancangan diagram sistem

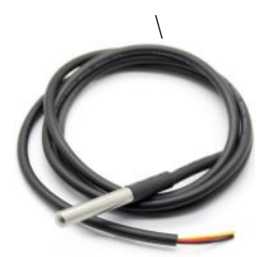

Gbr 3. Sensor DS18B20 Waterproof

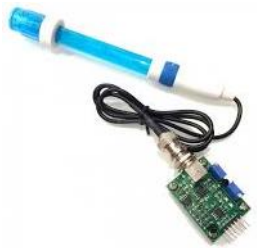

Gbr 4. Sensor pH Meter Analog Kit

\section{B. Rancangan Node Sensor}

Node sensor berfungsi sebagai node yang melakukan proses sensor terhadap lingkungan dimana Wireless Sensor Network diimplementasikan untuk memperoleh sejumlah data, yang kemudian dikirimkan ke server secara online melalui internet. Setiap node memiliki perangkat keras dan perangkat lunak yang mendukung proses sensor [1].
Node sensor yang disebar dirancang untuk dapat membaca data $\mathrm{pH}$ tanah, dan suhu dari lahan pertanian. Sensor-sensor yang digunakan adalah sebagai berikut:

1) Sensor DS18B20 Waterproof

Sensor suhu DS18B20 Waterproof adalah sensor suhu yang memiliki keluaran digital. DS18B20 memiliki tingkat akurasi yang cukup tinggi, yaitu $0,5^{\circ} \mathrm{C}$ pada rentang suhu $10^{\circ} \mathrm{C}$ sampai $+85^{\circ} \mathrm{C}$. Sensor suhu pada umumnya membutuhkan ADC dan beberapa pin port pada mikrokontroller, namun DS18B20 ini tidak membutuhkan ADC agar dapat berkomunikasi dengan mikrokontroller dan hanya membutuhkan 1 wire saja [8].

\section{2) Sensor pH Meter Analog Kit}

Sensor $\mathrm{pH}$ Meter Analog Kit adalah alat ukur pada tingkat keasaman cairan $(\mathrm{pH})$ yang menggunakan penginderaan pengukur standar industri sebagai komponen utamanya. Elektroda sensor terbuat dari membran kaca sensitif dengan impendasi kecil sehingga menghasilkan hasil pengukuran dengan respon cepat dan stabilitas terhadap suhu tinggi. Hasil pembacaan sensor bisa langsung diakses oleh mikrokontroler melalui antarmuka pH 2.0 yang terdapat pada sensor. Sensor ini sangat ideal untuk aplikasi pengukuran $\mathrm{pH}$ cairan dalam jangka panjang.

\section{Rancangan Node Gateway (Node Sink)}

Node gateway atau disebut juga dengan sink node merupakan node yang bertindak sebagai pintu gerbang keluar masuk (gateway) paket data yang dikirimkan oleh node sensor dan diterima oleh komputer pusat data (server). Node gateway meliki dua buah tugas utama, meliputi :

- Node gateway (node sink) bertugas untuk meneruskan paket data dari lapangan (data hasil sensor) ke database milik sistem Wireless Sensor Network (WSN). Data-data ini disimpan oleh node-node sensor, kemudian dikirimkan ke komputer server dengan melalui Node Gateway.

- Meneruskan paket data dari lapangan (data hasil sensor) dari satu node sensor ke node sensor lainnya. Kadang kala untuk sistem Peer to Peer (P2P), antar node sensor dapat saling memberikan data (bertukar data). Proses ini memerlukan peran dari Node Gateway, terutamanya untuk menghubungkan dua buah WSN atau lebih [1].

\section{IV.HASIL DAN PEMBAHASAN}

Dari rancangan yang dibuat, node sensor dibuatkan program yang ditanam pada Arduino UNO menggunakan Arduino IDE. Arduino yang telah diprogram dihubungkan dengan sensor DS18B20 Waterproof untuk membaca nilai suhu, $\mathrm{pH}$ Meter Analog Kit untuk membaca nilai $\mathrm{pH}$ tanah, serta modul ESP8266 untuk menghubungkan sensor node ke jaringan. Pengujian dilakukan untuk mengetahui hasil kerja perangkat dan sistem yang dirancang. Pengujian dilakukan dengan melakukan percobaan untuk melihat kemungkinan kesalahan yang terjadi dari setiap proses.

\section{1) Pengujian Sensor DS18B20 Waterproof}

Pengujian sensor DS18B20 Waterproof berfungsi untuk mengetahui akurasi dari perangkat pengukur suhu yang digunakan, sehingga diketahui nilai suhu air sawah yang 
sebenarnya. Bahan uji yang digunakan yaitu sampel air murni, air panas dan air dingin yang diasumsikan sebagai air sawah. Kemudian hasilnya akan dibandingkan dengan alat ukur Digital Thermostat With Probe. Hasil pengujian akurasi pengukuran suhu disajikan pada tabel I.

TABEL 1

Pengujian Pengukuran Suhu Tanah

\begin{tabular}{|c|c|c|c|c|}
\hline No & $\begin{array}{c}\text { Sampel } \\
\text { Air }\end{array}$ & $\begin{array}{c}\text { Sensor } \\
\text { DS18B20 } \\
\text { Waterproof }\end{array}$ & $\begin{array}{c}\text { Digital } \\
\text { Thermostat } \\
\text { With Probe }\end{array}$ & $\begin{array}{c}\text { Error } \\
(\%)\end{array}$ \\
\hline 1 & $\begin{array}{c}\text { Air } \\
\text { Dingin }\end{array}$ & 12.78 & 12.56 & 1.75 \\
\hline 2 & Air Murni & 29.62 & 29.60 & 0.07 \\
\hline 3 & Air Panas & 61.00 & 61.56 & 0.91 \\
\hline \multicolumn{5}{|c|}{ Rata-rata } \\
\hline
\end{tabular}

TABEL II

PenguJian PENGUKuRAn Ph TANAH

\begin{tabular}{|c|c|c|c|c|c|}
\hline No & $\begin{array}{c}\text { Sampel } \\
\text { Air }\end{array}$ & $\begin{array}{c}\text { pH } \\
\text { Meter } \\
\text { Analog } \\
\text { Kit }\end{array}$ & $\begin{array}{c}\text { Digital } \\
\mathbf{p H} \\
\text { Meter }\end{array}$ & Keterangan & $\begin{array}{c}\text { Error } \\
(\%)\end{array}$ \\
\hline 1 & $\begin{array}{c}\text { Air } \\
\text { Jeruk }\end{array}$ & 2.88 & 3.50 & Asam & 17.71 \\
\hline 2 & $\begin{array}{c}\text { Air } \\
\text { Murni }\end{array}$ & 6.39 & 6.80 & Normal & 6.03 \\
\hline 3 & $\begin{array}{c}\text { Air } \\
\text { Sabun }\end{array}$ & 10.84 & 10.60 & Basa & 2.26 \\
\hline \multicolumn{6}{|c|}{ Rata-rata } \\
\hline
\end{tabular}

Error $(\%)=\frac{\text { selisih nilai sensor dengan digital thermostat }}{\text { nilai digital thermostat }} \times 100 \%$

$$
\text { Akurasi }=100 \%-\text { rata }- \text { rata error }
$$

Berdasar persamaan 1 dan 2 maka nilai rata-rata error sensor suhu dengan sampel air dingin yaitu $1.75 \%$, dengan akurasinya adalah $98.25 \%$. Nilai rata-rata error sensor suhu dengan sampel air murni yaitu $0.07 \%$, sehingga nilai akurasinya adalah $99.93 \%$. Pada sampel dengan air panas diperoleh nilai rata-rata error-nya yaitu $0.91 \%$ dan nilai akurasinya adalah $99.09 \%$. Dari hasil pengujian dengan ketiga sampel air tersebut maka diperoleh rata-rata akurasi sensor DS18B20 yaitu $99.09 \%$, sehingga dapat disimpulkan bahwa kinerja dari sensor sudah bekerja secara efektif.

\section{2) Pengujian Sensor $p H$ Meter Analog Kit}

Pengujian sensor pH Meter Analog Kit dilakukan dengan menaruhkan probe sensor $\mathrm{pH}$ ke dalam tiga buah gelas yang berisi air murni, air jeruk dan air sabun yang diasumsikan sebagai air persawahan. Selanjutnya sensor $\mathrm{pH}$ air dihubungkan ke perangkat pengendalian Arduino Uno dan hasilnya ditampilkan melalui LCD kemudian dilakukan dengan membandingkan alat ukur $\mathrm{pH}$ Meter - Pen Type $\mathrm{PH}-$ 009. Hasil pengujian akurasi pengukuran $\mathrm{pH}$ disajikan pada tabel II
Dari persamaan 1 dan 2, diperoleh nilai rata-rata error sensor $\mathrm{pH}$ dengan sampel air jeruk yaitu $17.71 \%$, sehingga akurasinya adalah $82.29 \%$. Nilai rata-rata error sensor suhu dengan sampel air murni yaitu $6.03 \%$, dan nilai akurasinya adalah $93.97 \%$. Pada sampel dengan air sabun nilai rata-rata error-nya yaitu $2.26 \%$ dan nilai akurasinya adalah $97.74 \%$. Dari hasil pengujian dengan ketiga sampel air tersebut maka diperoleh rata-rata akurasi sensor pH Meter Analog Kit yaitu $91.33 \%$, sehingga dapat disimpulkan bahwa kinerja dari sensor sudah bekerja secara efektif.

\section{V.KESIMPULAN}

Berdasarkan hasil penelitian yang dirancang dapat diambil kesimpulan bahwa penggunaan Wireless Sensor Network berbasis Internet of Things (IoT) dapat membantu untuk memantau kualitas air dan tanah dari lahan pertanian menjadi lebih efisien. Penggunaan modul ESP8266 sebagai modul WIFI dapat mengurangi biaya karena harganya yang relatif murah serta kecepatan pengiriman datanya cukup baik yaitu sebesar $80 \mathrm{MHz}$. Tingkat akurasi dari sensor yang digunakan yaitu sensor DS18B20 Waterproof untuk pengukuran suhu sebesar $99.09 \%$ sedangkan pengukuran $\mathrm{pH}$ menggunakan sensor $\mathrm{pH}$ Meter Analog Kit sebesar 91.33\%. Hal ini menunjukkan bahwa sensor-sensor yang digunakan sudah cukup akurat. Untuk penelitian selanjutnya perlu dilakukan penambahan sensor-sensor yang digunakan untuk mengetahui kadar unsur hara pada tanah yaitu N, P, K (natrium, fosfor dan kalium) sehingga dapat membantu petani untuk melakukan pemupukan pada lahan pertaniannya

\section{UCAPAN TERIMAKASIH}

Penulis menghaturkan rasa hormat dan terimaa kasih kepada pihak-pihak yang telah membantu menyelesaikan penelitian ini, serta kepada rekan peneliti yang membantu dan memberi dukungan sehingga penelitian dapat terlaksana dengan baik.

\section{DAFTAR PUSTAKA}

[1] http://repository.uksw.edu/bitstream/123456789/9094/2/T1 52201170 1_BAB\%20II.pdf (diakses 08 Mei, 2018)

[2] Pratama, I Putu Agus Eka, and Suakanto, Sinung. "Wireless Sensor Network". Informatika. Bandung. 2015.

[3] Saputra, Teuku Ridha Muhammad, Syaryadhi, Mohd, And Dawood, Rahmad, SNETE, https://www.researchgate.net/publication/320518805 2017, (diakses: March 28, 2018)

[4] Sridharan, S. "Water Quality Monitoring System Using Zigbee Based Wireless Sensor Network." International Journal of Engineering \& Technology, 9(10), 14-18. 2014

[5] Fuad, M. "Rancang Bangun Wireless Sensor Network Berbasis Protokol Zigbee dan GSM untuk Sistem Pemantauan Polusi Udara," (Tesis, IPB). 2015.

[6] Sabiq, A., And Alfarisi, T. "Sistem Wireless Sensor Network Berbasis Arduino Uno dan Raspberry Pi untuk Pemantauan Kualitas Udara di Cempaka Putih Timur, Jakarta Pusat”, 301-305. 2017.

[7] Aksara, J., Politeknik, E., \& Riau, C. Sistem Pemantauan Kondisi Tanah Sawah Sebagai Referensi Pemupukan Padi Berbasis Wireless Sensor Network. In Seminar Nasional dan Expo Teknik Elektro 2017 (Vol. 4). 2015.

[8] Pratama, Rizki Priya. "Aplikasi Webserver ESP8266 untuk Pengendali Peralatan Listrik." INVOTEK (Jurnal Inovasi, Vokasional dan Teknologi), 17(2), pp.39-44. 2017.

[9] Rahmat, Basuki., Mindari, Wanti., And Sasongko, Purnomo, SANTIKA, 
Https://Www.Researchgate.Net/Publication/313244730_Sistem_Perta nian_Cerdas_Berbasis_Internet_Based_Data_Acquisition_And_Contr ol_System_Idacs, (diakses: Mei 07, 2018)

[10] Ellia, Nurazizah., Ramdhani, Muhammad., And Rizal, Achmad. "Rancang Bangun Termometer Digital Berbasis Sensor DS18B20 Untuk Penyandang Tunanetra (Design Digital Thermometer Based on
Sensor DS18B20 For Blind People)", E-Proceeding of Engineering. (pp. 3294-3301). 2017.

[11] Roihan, Ahmad,. And Damyati, Muhammad Asep,. "Prototipe Automatic Air Filtration Mikrokontroler Atmega328 Sebagai Air Quality Control." JPIT (Jurnal Pengembangan IT), 03(01). 2018. 